\title{
Polimorfismo das lesões dermatológicas na blastomicose de Jorge Lobo entre os índios Caiabí
}

\author{
PaUlo de Almeida Machado \\ Instituto Nacional de Pesquisas \\ da Amazônia
}

\begin{abstract}
SINOPSE
São estudados casos de blastomicose de Jorge Lobo encontrados entre índios Caiabi vivendo numa alcieia nativa à margem do rio Tatui (Amazônia Mato Grossense). Aqueles índios não devem ser confundidos com os Caiabi estudados por outros Autores no Parque do Xingu. Foram encontrados cinco quadros dermatológicos distintos e que o Autor divide em dois grupos polares : um grupo hiperêrgico (formas maculosas e gomosas) e um grupo hipoergico, forma queloidiforme. $\hat{\mathrm{E}}$ enfatizada a conveniencia do estudo da classificação das formas clínicas, já proposta por D. Silva, como elemento básico para melhor interpretação das diferentes observações e como ponto de partida para pesquisas imunológicas indispensáveis à melhor compreensão da Doença de Jorge Lobo.
\end{abstract}

\section{MATERIAL E MÉTODOS}

Foram examinados índios Caiabi encontrados em uma aldeia nativa à margem esquerda do rio Tatui. Aquele rio é também denominado rio dos Peixes ou rio S. Francisco em certos mapas. A aldeia encontra-se a cerca de $20 \mathrm{~km}$ da confluência do Tatui com o Arinos, aproximadamente a $57^{\circ} 58$, de longitude oeste e $10^{\circ} 40$ de latitude sul, a cerca de $400 \mathrm{~km}$, em linha reta, a oeste do Parque Nacional do Xingu.

Os índios considerados neste trabalho năo devem ser confundidos com outros Caiabi, portadores de blastomicose de Jorge Lobo e des. critos por outros Autores no Parque Xingu ( $\mathrm{Pe}$ reira Filho, 1957 e Baruzzi e cols, 1967). Não foi possível determinar a população da aldeia uma vez que a expedição foi realizada durante a estação de caça e cada dia chegavam ou partiam alguns habitantes. Uma estimativa em termo de 40 pessoas seria bastante aproximada da realidade.
O exame consistiu na inspeçäo e palpação dermatológica, exame da cavidade oro-faringéa e procura de ganglios palpáveis. Foi feita a biopsia em todos os casos com lesões não passíveis de diagnóstico imediato: um caso típico de tokelau e um caso com lesão queloidiforme típica deixaram de ser biopsiados. material foi sempre colhido junto aos bordos da lesão, à exceção de nódulos profundos que foram removidos após dissecção. O material foi imediatamente colocado em formol a $10 \%$ e transportado para S. Paulo, onde, três semanas depois, foi confiado ao Dr. Decio Fleury da Silveira para exame histopatológico. A anamnese foi sumária, em virtude da barreira linguistica.

\section{Resultados}

Em um só paciente foi encontrada lesão queloidiforme. Tratava-se de lesão única localizada na regiäo sacro-glutea (Fig. 1).

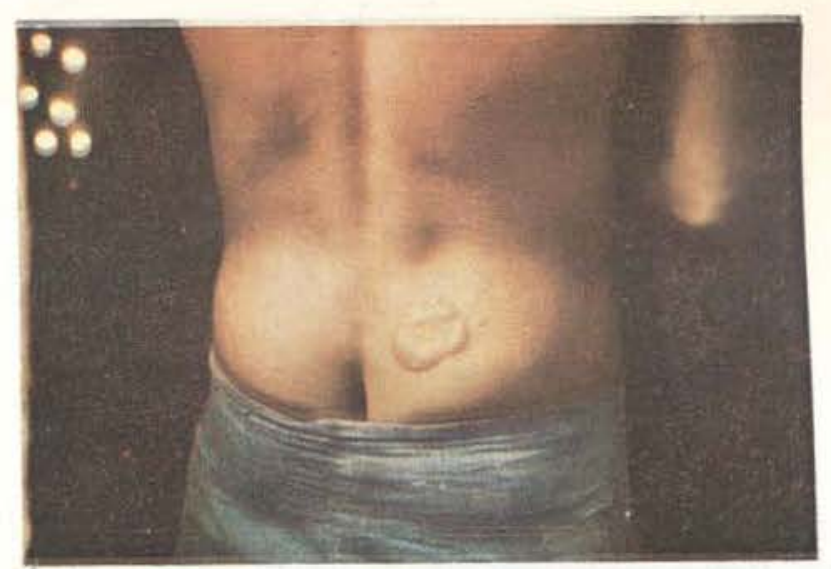

Fig. 1 - Lesẫo queloidiforme, Caiabi, do rio Tatui (Foto P. A. Machado) 
Em um jovem de provavelmente 15-17 anos. foi vista, ao nível da omoplata direita, uma lesão inconspicua, que teria passado ciesapercebida Somente foi notada graças à cooperação de uma senhora idosa que, respondendo à pergunta "Como começa o piraip?" chamou o jovem e apontou para o seu ombro. Tratava-se de uma área circular irregular, com bordes pouco definidos, onde a pele não apresentava a secreção sebacea conferindo brilho ao restante do tegumento cutâneo. Não havia infiltração, discromia nem hiperemia. Aquela lesăo foi denominada "incaracterística" e a biopsia foi feita na suposição de tratar-se de uma forma indeterminada de hanseniase, tendo o resultado da his. topatologia consistido numa surpresa, revelando o quadro histológico típico da micose de Lobo, com extraordinária riqueza em parasitos. Ao praticar a biopsia foi notado que o tecido sangrava com mais abundância do que o que se costumava presenciar ao biopsiar lesões de hanseniase.

Em dois casos, ambos do sexo feminino e do grupo etário 20-30 anos, e sempre no antebraço, foram encontrados nódulos duros, não aderentes ao plano superficial e somente detectáveis à palpação. Feita a exerese por dissecção constatou-se tratar-se de nódulos ovoides, com 15 a $20 \mathrm{~mm}$ em seu maior diâmetro, duros. Seccionando-os, verificou-se ser o seu conteúdo de cor amarela, consistente e firme. Uma das pacientes portava um nódulo único e nenhuma outra lesão. Na outra paciente havia dois nódulos, distanciados de $8 \mathrm{~cm}$ e sem qualquer comunicação visível entre ambos. Os nódulos eram indolores. A histopatológia revelou riqueza em parasitos. (Machado, 1966)

Em dois outros casos, foram encontradas lesões gomosas multiplas, com ou sem ulceração. Nos portadores de lesões gomosas não foram encontradas lesões de outro tipo. (Fig. 2 e Fig. 3).

Nos cašos restantes, as lesões eram do tipo anteriormente descrito (Machado 1972) como forma maculosa: lesões únicas ou múltiplas, em diferentes estágios evolutivos.
Havia desde a mácula circinada com bordos ligeiramente hiperenicos, (Fig. 4), até máculas infiltradas, turgidas, (Fig. 5) e lesões que

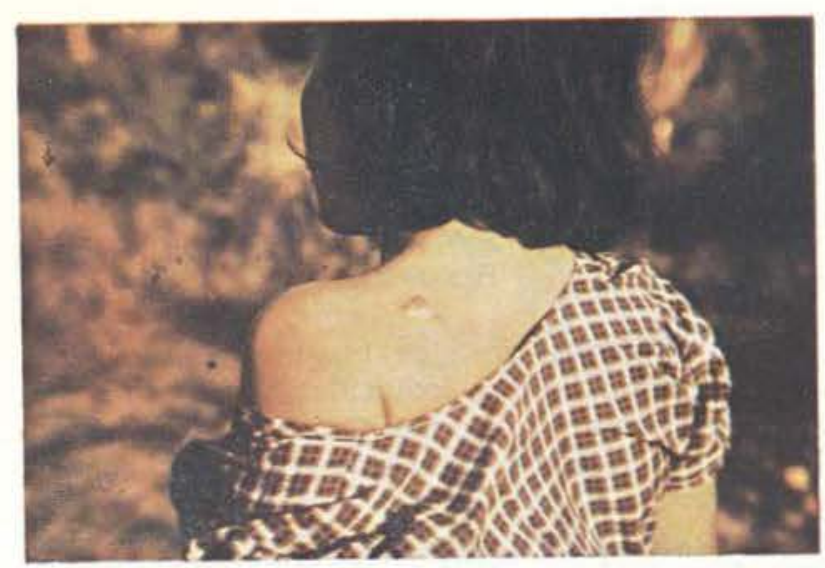

Fig. 2 - Lesões gomosas, Caiabí, do rio Tatuí. (Foto P. A. Machado)

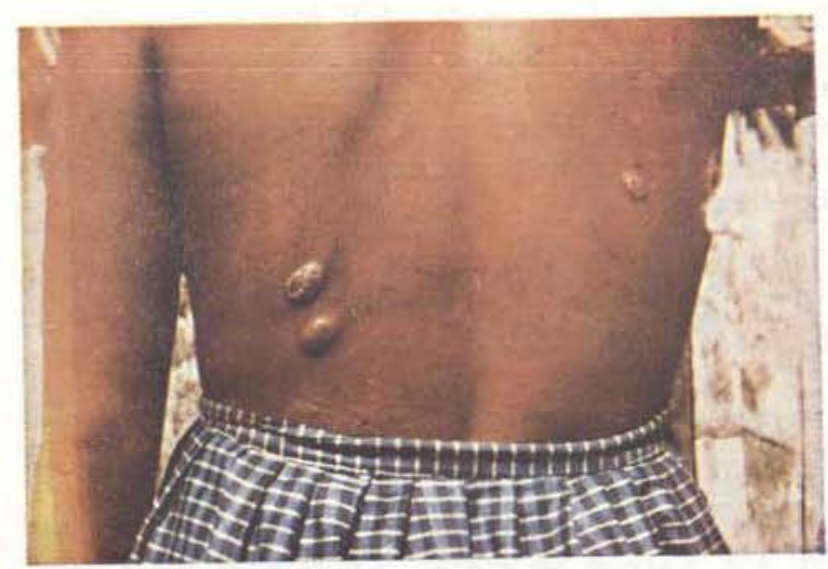

Fig. 3 - Lesôes gomosas evoluindo para a supuração Caiabí do rio Tatuí. (Foto P. A. Machado)

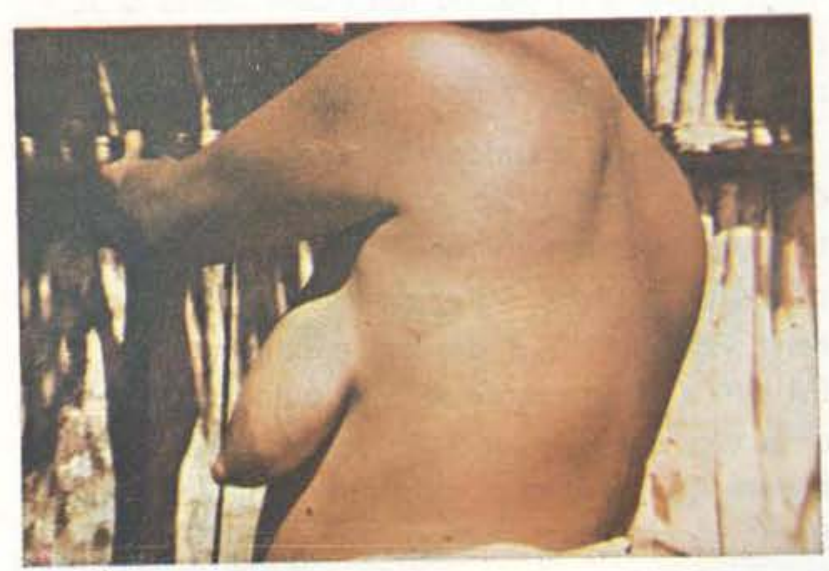

Fig. 4 - Lesão maculosa única, inicial, estágio-préinfiltrativo - Caiabí do rio Tatuí. (Foto P. A. Machado) 
passaram a fase de turgescencia e apresentavam pontos onde se daria eliminaçäo de um fluí. do caseoso (Fig. 6). Em alguns pacientes há lesões maculosas multiplas em diferentes estágios (Fig. 7). Com frequência nota-se evidente atividade" da lesão (Fig. 8). Em casos já antigos encontram.se, ao lado de lesões em franca atividade, lesões cicatriciais, aparentemente curadas (Fig. 9). Em todos os casos, o exame histopatológico revelou a mesma riqueza em pa. rasitos. Lesões localizadas na cabeça ou no pescoço, não foram encontradas, embora as oreIhas sejam tradicionalmente citados como a localização preferencial da micose de Jorge Lobo.

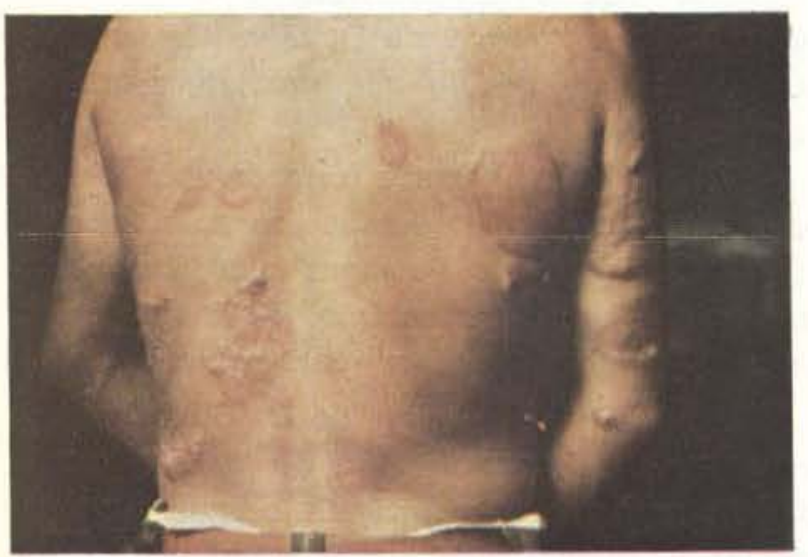

Fig. 5 - Lesõ̃es maculosas em direrentes estágios evolutivos, máculas infiltradas no braço - Caiabí do rio Tatuí.

(Foto P. A. Machado)

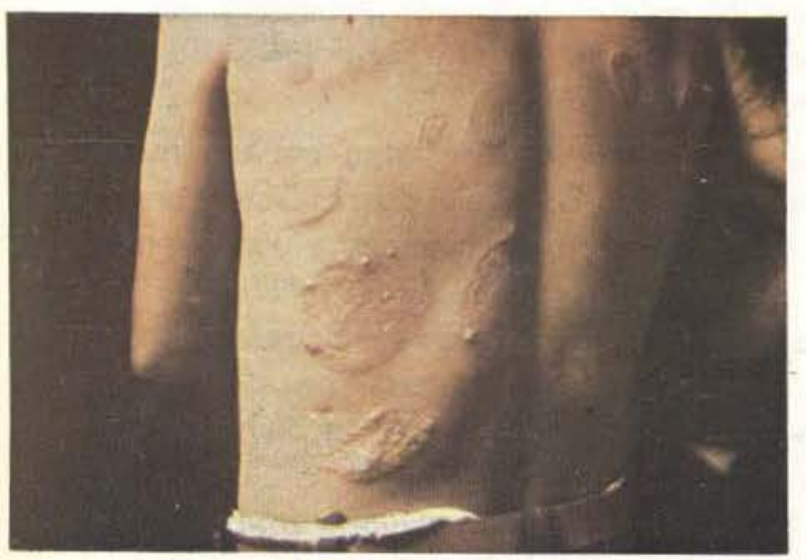

Fig. 6 - Lesōes maculosas em diferentes estados evolutivos, notar os diferentes graus de infiltração e os pontos de supuração em formação sobre o bordo da lesão após desaparecimento da infiltração generalizada da lesão Caiabí do rio Tatui. (Foto P. A. Machado)

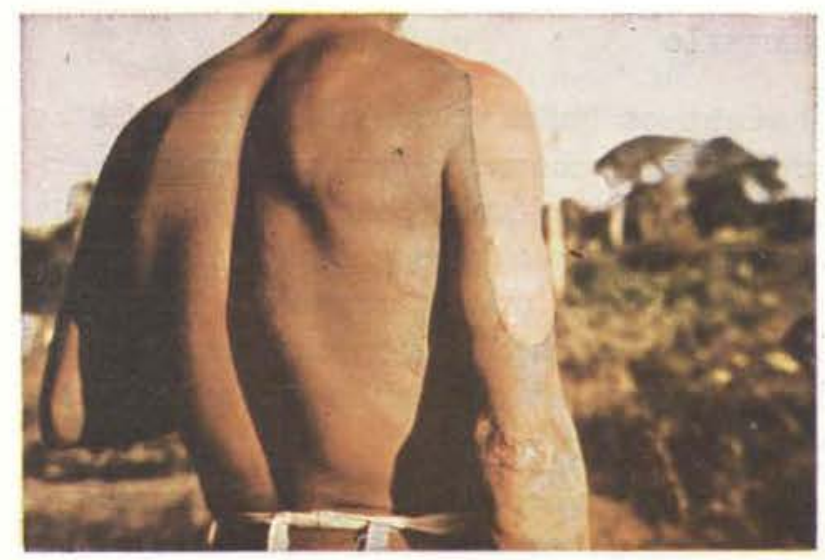

Fig. 7 - Diferentes estágios evolutivos das lesōes maculosas: lesões iniciais, porém já infiltradas, no tronco; lesôes maculosas em via de supuração no braço e lesôes cicatriciais no cotovelo - Caiabí do rio Tatuí. (Foto P. A. Machado)

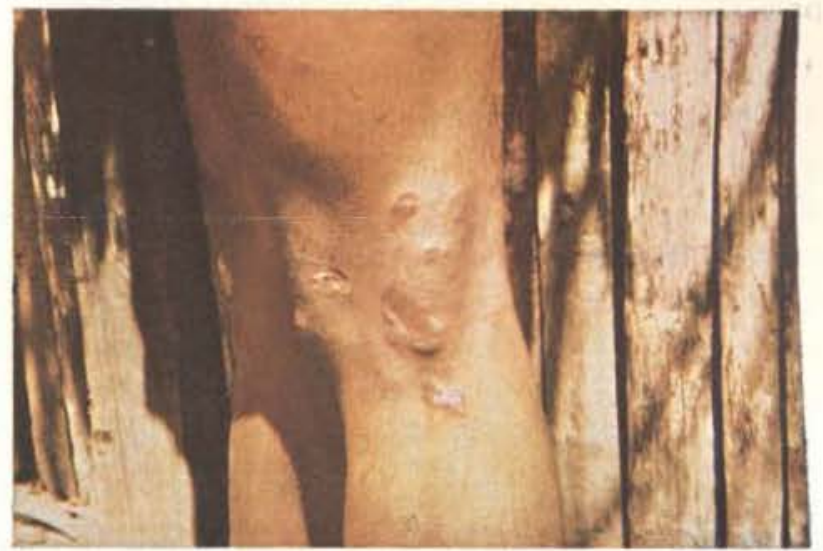

Fig. 8 - Lesão maculosa em atividade, estágio post-infiltrativo; regredida a infiltração, formam-se pontos de supuração - Caiabí do rio Tatuí. (Foto P. A. Machado)

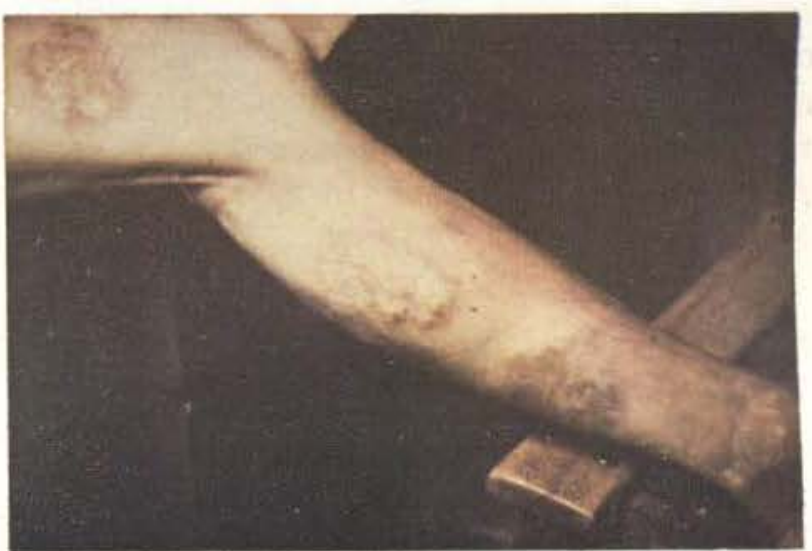

Fig. 9 - Lesões maculosas na perna. Lesões cicatriciais na região maleolar e no terço inferior da coxa, lesão macular na região da pantorilha, em estágio post-infiltrativo, com formação de pontos de supuração. No terço inferior da perna existe lesão cicatricial hipercronica certamente de origem inespecífica. Caiabí do rio Tatuí. (Foto P. A. Machado) 


\section{DISCUSSÃO}

Entre os índios Caiabí, a blastomicose de Jorge Lobo é encontrada com quadros dermatológicos muito variáveis, polimorfos, e somente o exame histopatológico permitiu demonstrar tratar-se de uma única parasitose. Compreende-se que Pereira Filho (op.cit.) tenha considerado a doença dos Caiabí como outra blastomicose.

A multiplicidade dos quadros dermatológicos é mais um argumento a favor da oportunidade de uma classificação das formas clínicas na blastomicose de Lobo. D. Silva (op cit) foi o primeiro a tentar aquela classificação, fazendo-o com a autoridade de quem tem a maior experiência da blastomicose de Lobo entre nós.

A classificação das formas clínicas e a adoção de uma nomenclatura única irá permitir o melhor intercämbio de informaçốes e sobretudo irá constituir a base indispensável ao desenvolvimento de pesquisas imunológicas altamente necessárias ao melhor conhecimento da enfermidade. Se bem que haja indiscutive! embricamento de certas formas clinicas, como com muita propriedade notou D. Silva, é certo que as diferentes formas clínicas até hoje descritas sugerem a existência de dois comportamentos diferentes nas interações agente-hospedeiro. Em um tipo de comportamento, existe uma reação evidente do organismo, com ten. dência à eliminação do parasita num caseum amarelo por vezes sanguinolento. O organismo parece rejeitar o agente. Existe uma disseminação provavelmente hematogênıca com multiplicidade de lesões, como se vê nas fig. 6 e 7 As lesões teem caráter evolutivo (Machado 1972).

O outro tipo caracteriza-se por uma certa complascencia do organismo. Não há tendencia à produção de caseum e à eliminação do germe que permanece aparentemente tranquilo em lesões localizadas com pouca ou nenhuma tendência invasora, lesões geralmente únicas. (Fig. 1). Não existe caráter evolutivo embora possa haver crescimento das lesões e ampliação da área doente.

O primeiro tipo, onde existe um comportamento que chamariamos hiperergico, é constitui- do fundamentalmente pela forma maculosa. A forma gomosa seria também um tipo hiperergico. No tipo diametralmente oposto, hipoérgi$\mathrm{co}$, situariamos as formas queloidiformes e verruciformes. A lesão incaracteristica mencionada neste trabalho seria apenas o estágio inicial da forma maculosa.

Já a forma nodulosa, que não figura na classificação de D. Silva, e que foi registrada também por Baruzzi e cols. (op. cit), necessitaria de mais estudos e observações para ser melhor situada. Nos dois casos citados neste trabaIho, não havia tendência à caseificação e ulceração, pelo menos no estágio observado. Já no caso 3 de Baruzzi, pode-se supor uma possibilidade de ulceração futura. $O$ caso documentado à figura 9 de D. Silva (op.cit) não teria sido um nódulo que posteriormente se ulcerou?

Apesar da impressão formada após o estudo dos dois casos citados no presente trabalho. as observações dos colegas que documentaram casos em outro estágio, dá impressão de que os nódulos caminham para a ulceração.

A fig. 7 do trabalho de D. Silva, mostra um nódulo ulcerado próximo de lesão gomosa. A foto reveste de importância e sugere um pa. rentesco imunológico entre nódulo e goma, podendo ser o nódulo uma manifestação hiperergica. De maneira geral, nos casos maculosos não encontramos lesôes queloidiformes ou verruciformes, e vice-versa. O fato é sugestivo da existência de um substrato imunológico caracterizando dois tipos polares de blastomicose de J Lobo.

As observações feitas em um núcleo pequeno como a aldeia do rio Tatui, onde o reduzido número de pessoas vivendo em idênticas condições indica como mais lógico o parasitismo por uma única cepa, reforça a suposição de que as diferentes formas clínicas se devam a uma reação diferente de parte do organismo parasitado.

A histopatologia deveria preocupar-se com Este aspecto e a imunologia deveria interessar se também pela blastomicose de Lobo.

No entretanto, é da maior oportunidade o esforço pioneiro de D. Silva no sentido de procurar uma classificação para as formas clini- 
cas, estabelecer uma nomenclatura comum e fornecer a base indispensável ao desenvolvimento da pesquisas imunológica.

A título de contribuição, sem o intuito de contestar mas com a preocupaçâo de apoiar a classificação de D. Silva, e com todo o respeito que merece a opinião daquele mestre, parece-nos admissível a seguinte classificaçắo das formas clínicas até hoje encontradas na blastomicose de Lobo:

$\begin{aligned} & \text { formas hiperergicas : } \begin{array}{l}\text { incaracterstica (?) } \\ \text { maculosa } \\ \text { gomosa } \\ \text { nodulosa (?) }\end{array} \\ & \text { formas hipoergicas : } \text { queloidiforme } \\ & \text { verruciforme }\end{aligned}$

A classificação proposta evita a expressão "infiltrativa" uma vez que, segundo observação de D. Silva, a infiltração ocorre năo só na forma maculosa como também nos prodromos da forma queloidiforme. E na própria forma maculosa, a infiltração é um episódio: surge e desaparece, permanecendo a mácula.

A forma incaracterística é citada com um ponto de interrogação. Só existe um caso descrito, sem follow-up, e não é fácil prever se a lesão irá evoluir para uma forma queloidiforme ou para uma lesão maculosa. Pela sua extenisão, parece que evoluiria para a forma maculo. sa, mas á falta de dados científicos, não é possível afirmar e justifica-se a dúvida.

Também está seguida de um ponto de interrogação a forma nodulosa que necessita de mais acuradas observações para ser situada entre as formas hipóergicas icomo parece nos casos de nossa observação) ou nas formas hiperergicas (como o indicam as observações de outros colegas).

Entre os índios Caiabí do rio Tatui, predominam as formas hiperergicas.

\section{ABSTRACT}

Different clinical aspects of Lobo's disease among Caiabi Indians are described. The patients were seen in a native village, outside the Parque Nacional áo Xingú, $400 \mathrm{~km}$ West of said Reservation. Distinct dermatological aspects were found.

Some dermatological aspects are suggestive of an intense immunological reaction, lesions are evolutive and caseification and ellimination of parasites occurs. There are multiple lesions and an invasive behaviour of the disease. Such cases are classified as a hypperergic group of clinical manifestations. In other group of dermatological aspects, there is a certain tolerance between the system and the pathogenic organism. Lesion is usually an isolated only one. There is no tendency to caseification and suppuration. The invasive characteristic is absent. This group of dermatological pictures is supposed to be a hypoergic group. classification of dermatological pictures, as attempted for the first time by D. Silva and establishment of a nomenclature is emphasized as a most convenient step in order to facilitate scientific comparison of case descriptions and to establish a starting point for sound immunological research on Lobo's disease

\section{BIBLIOGRAFIA CITADA}

BARUZZI, R. G. ET ALII

1967 - Ocorrência de blastomicose queloideana entre índios Caiabi. Rev. Inst. Med. Trop. S. Paulo, $9(3): 135-142$.

MaChado, P. A.

1966 - "Piraip, a falsa lepra dos Caiabi". In : XVI Cong. Bras. Hig., Curitiba, Paraná.

1972 - Regressão expontânea e lesões maculosas na Blastomicose de Jorge Lôbo. Acta Amazonica, Manaus, 2(2).

Pereira Filho, M. J.

1957 - Os fungos da doença de Adolfo Lutz, da Doença de Jorge Lôbo e o da blastomicose dos índios do Alto Xingu (Brasil-Central - Estado de Mato Grosso). Rev. Med. Rio Grande do Sul, $14: 10-64$.

Silva, D.

1972 - Micose de Lobo. Rev. Soc. Med. Trop. 6 (2) : 85-98. 